\title{
Differentiating current and past PCB and PCDD/F sources: The role of a large contaminated soil site in an industrialized city area ${ }^{2 / 2}$
}

\author{
Antonio Di Guardo a, *, Elisa Terzaghi a , Giuseppe Raspa ${ }^{b}$, Sara Borin ${ }^{\mathrm{c}}$, Francesca Mapelli ${ }^{\mathrm{c}}$, \\ Bessem Chouaia ${ }^{\mathrm{c}, 1}$, Elisabetta Zanardini ${ }^{\mathrm{a}}$, Cristiana Morosini ${ }^{\mathrm{a}}$, Andrea Colombo ${ }^{\mathrm{d}}$, \\ Elena Fattore ${ }^{\mathrm{d}}$, Enrico Davoli ${ }^{\mathrm{d}}$, Stefano Armiraglio ${ }^{\mathrm{e}}$, Vanna M. Sale ${ }^{\mathrm{f}}$, Simone Anelli ${ }^{\mathrm{f}}$, \\ Paolo Nastasio ${ }^{\mathrm{f}}$

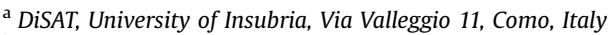 \\ b DCEME, Sapienza University of Rome, Via Eudossiana 18, Rome, Italy \\ ${ }^{c}$ DeFENS, University of Milan, Via Celoria 2, Milan, Italy \\ d Department of Environmental Health Sciences, IRCCS-Istituto di Ricerche Farmacologiche "Mario Negri", Via La Masa 19, Milan, Italy \\ e Municipality of Brescia - Museum of Natural Sciences, Via Ozanam 4, Brescia, Italy \\ ${ }^{\mathrm{f}}$ ERSAF, Via Pola 12, Milan, Italy
}

\section{A R T I C L E I N F O}

\section{Article history:}

Received 9 November 2016

Received in revised form

13 January 2017

Accepted 15 January 2017

Available online 22 January 2017

\section{Keywords:}

Brescia-Caffaro

Fate modelling

SoilPlus

Fingerprint

Contaminated site

Microbiological profiling

\begin{abstract}
A B S T R A C T
Cities and contaminated areas can be primary or secondary sources of polychlorinated biphenyls (PCBs), dibenzo-p-dioxins (PCDDs), dibenzofurans (PCDFs), and other chemicals, into air and soil and can influence the regional level of some of these pollutants. In a contaminated site, the evaluation of such emissions can be crucial in the choice of the remediation technology to be adopted. In the city of Brescia (Northern Italy), more than 100 ha of agricultural areas were contaminated with PCBs, PCDD/Fs and heavy metals, originating from the activities of a former PCB factory. In order to evaluate the current emissions of PCBs and PCDD/Fs from the contaminated site, in a location where other current sources are present, we compared measured and predicted air concentrations, resulting from chemical volatilization from soils as well as fingerprints of Brescia soils and of soils contaminated by specific sources. The results confirm that the contaminated area is still a current and important secondary source of PCBs to the air, and to a lesser extent of PCDFs (especially the more volatile), but not for PCDDs. PCBs in soils have fingerprints similar to highly chlorinated mixtures, indicating contamination by these mixtures and/or a long weathering process. PCB 209 is also present at important levels. PCDD fingerprints in soil cannot be related to current emission sources, while PCDFs are compatible to industrial and municipal waste incineration, although weathering and/or natural attenuation may have played a role in modifying such soil fingerprints. Finally, we combined chemical and microbiological analyses to provide an integrated approach to evaluate soil fingerprints and their variation in a wider perspective, which accounts for the mutual effects between contamination and soil microbiota, a pivotal hint for addressing in situ bioremediation activities.
\end{abstract}

๑) 2017 Elsevier Ltd. All rights reserved.

\section{Introduction}

Halogenated organic compounds were extensively used in industry and agriculture and they or their by-products are common

\footnotetext{
This paper has been recommended for acceptance by Dr. Chen Da.

* Corresponding author.

E-mail address: antonio.diguardo@uninsubria.it (A. Di Guardo).

1 Current address: DISAA, University of Milan, Via Celoria 2, Milan, Italy.
}

contaminants in all environmental matrices. Some of them have been recognized as POPs (Persistent Organic Pollutants, now banned by the Stockholm Convention), harmful to the ecosystems and human health. POPs, such as polychlorinated biphenyls (PCBs), dioxins (PCDDs), furans (PCDFs), are extremely recalcitrant to the biodegradation and they also biomagnify in the food web. PCBs are a group of 209 congeners, known for genotoxic effects, immune suppression, inflammatory response, and endocrine disrupting effects (WHO/IPCS, 1993). The International Agency for Research on Cancer (IARC) Working Group, in 2013, classified PCBs as 
carcinogenic to humans (Group 1) (IARC, 2015).

More than 1,800,000 potentially contaminated sites have been identified in Europe (EEA, 2007). Among those, many are large scale sites. In Italy, there are 39 of such sites (SIN, so called "Siti di Interesse Nazionale" or National Priority Sites). The SIN Brescia Caffaro is located in the city of Brescia (a highly industrialized city of about 200,000 inhabitants in the Lombardy Region, in the north of Italy), originated by the activities of the former Caffaro S.p.A. chemical factory, which produced PCBs and PCB mixtures, such as Fenclor and Apirolio, between 1930 and 1984. The SIN perimeter was defined in 2003 by the Italian Ministry of Environment and, among other areas, more than 100 ha of agricultural areas (Fig. SI 1a), located south of the Caffaro factory, were found contaminated by a mixture of PCBs, PCDDs, PCDFs and heavy metals and metalloids ( $\mathrm{Hg}, \mathrm{As})$ in variable concentrations, often exceeding the legal threshold for residential areas (e.g. for PCBs: $60 \mu \mathrm{g} / \mathrm{kg}$ dry weight (d.w.)). Such contamination was mostly related to the use of outflowing water from the factory, which ended up in the canals used to irrigate the adjacent fields. In the last two decades, a number of studies were conducted in this area to investigate PCB contamination of drinkable water (Turrio-Baldassarri et al., 2005), human blood (Apostoli et al., 2005; Donato et al., 2006; TurrioBaldassarri et al., 2008), soil and forage (Turrio-Baldassarri et al., 2007), cow milk (Turrio-Baldassarri et al., 2009), fetal tissues (Bergonzi et al., 2009), and air (Colombo et al., 2013). The clean-up of this site is therefore a priority for local and national authorities. However, the choice of the remediation methodology to be implemented (e.g. thermal desorption, excavation and disposal etc. vs. bioremediation processes) is crucial since any of these processes can produce reemission of POPs to the environment. A number of investigations have found out that cities and contaminated areas can be secondary sources of PCBs, PCDDs/Fs and other chemicals (Jamshidi et al., 2007; Weber et al., 2008; Bogdal et al., 2014; Zhang et al., 2014; Diefenbacher et al., 2016) to air and soil and can be capable to influence the regional level of some of these pollutants even at larger distances from sources, although the role of primary emissions can be still relevant (Jamshidi et al., 2007; Csiszar et al., 2013; Glüge et al., 2016). Recently, for another PCB production in Europe (Slovakia) the relevance of the source on impacting human health was shown measuring 15 PCBs in blood serum up to $50 \mathrm{~km}$ in the prevailing wind direction from the factory (Wimmerová et al., 2015).

In this work, in order to evaluate current emissions of PCBs and PCDD/Fs of the contaminated site (e.g. secondary emission) in a location where other sources (primary emissions) are present (e.g. industrial as well as a large municipal waste incinerator), we measured representative soil concentrations in three agricultural areas of the SIN. These concentrations were then used as starting soil loadings in a dynamic air/soil model developed by our group (SoilPlus) (Ghirardello et al., 2010) to predict air concentrations, resulting from chemical volatilization from soils, which were compared to measured air concentrations (Colombo et al., 2013). SoilPlus implements a dynamic air compartment which varies hourly according to the planetary boundary layer (PBL) and therefore can be used to reproduce realistic air concentrations of chemicals volatilizing from a contaminated soil, taking into account the seasonal and diel lower air compartment variation, e.g. simulating the conditions of the air sampling. This was shown to be a necessary step to accurately predict the variation of air concentration of PCBs in the air of the city of Zurich measured at a few hour time intervals (Morselli et al., 2011). These data, together with soil concentrations were analyzed using Principal Component Analysis (PCA), an exploratory multivariate data analysis technique used in several investigations in the last decades (Fattore et al., 1997, 2003) to identify the source of PCB and PCDD/F contamination on the basis of the relative ratio of the congeners or homologues classes, which represent a sort of fingerprint of the origin of the contamination (Johnson et al., 2006).

The objective of this study is therefore to provide and illustrate an integrated methodology to differentiate emissions in historical and current POP contamination situations. This was done, using the Brescia case, to evaluate the potential influence of the agricultural areas on the current air contamination for PCBs, PCDD/F and the relevance of primary vs. secondary emissions. Additionally, we compared the fingerprints of the chemical investigated to the fingerprints of the bacterial species composition detected in the same soil to further classify the areas and furnish a potential guidance for bioremediation. Although most of the efforts of this study were related to the comparison of $\mathrm{PCB}$ and $\mathrm{PCDD} / \mathrm{F}$ behavior, the additional results on trace elements as well as on volatile organic compounds (VOCs) will be reported.

\section{Experimental}

\subsection{Sampling and statistical design}

Soil was sampled in three different agricultural fields located in the SIN Brescia Caffaro contaminated site, south west of the Caffaro factory, at about $2.2 \mathrm{~km}$ from the center of the city (Graphic abstract and Fig. SI 1a). The total area of the contaminated agricultural areas in the SIN is around 100 ha, while the sampled fields were about 10 ha each. In order to collect representative samples of the area 15 subsamples of the top $(0-20 \mathrm{~cm})$ layer and 15 subsamples of deeper soil (50-70) were collected for each area using a random stratified grid scheme (Fig. SI 1b) with a $40 \mathrm{~mm}$ soil auger (Bipartite gouge auger set SA, Eijkelkamp, Giesbeek, The Netherlands). The objective was to collect few samples representative of the average concentrations in soils in order to catch the contaminants in the arable layer $(0-30 \mathrm{~cm})$ and those which may have migrated downwards during the long contamination period. The thirty subsamples were thoroughly mixed to obtain a representative pooled sample for each area (A, T and R in Fig. SI 1a) for the chemical and microbiological analyses.

Air concentrations were measured previously (Colombo et al., 2013) with a high-volume sampler at five sites: outside the industrial plant site (point B) and at increasing distances (from 0.4 to $1.2 \mathrm{~km}$ ), including the contaminated agricultural areas (points $A$ and D). Point E was located at the $1.2 \mathrm{~km}$ distance, away from the SIN areas. Sampling periods were between August 2007 and April 2008.

\subsection{Analytical methods}

Complete analytical methods are available in supporting information (S-I): briefly, PCBs and PCDD/Fs were extracted using the ASE 300 (Dionex,USA) with hexane/acetone (80/20), and separated from interfering components in a multistage process which included a purification step by an diatomaceous earth (70-230 mesh) loaded with concentrated sulphuric acid (98\%), and further purification on neutral alumina columns activated at $400{ }^{\circ} \mathrm{C}$ before use. The pollutants were detected by a TRACE GC 2000, Thermo Finnigan (Thermo Fisher Scientific), coupled with a Mat 95 XP Mass Spectrometer, operating in the electron impact ionization $(\mathrm{EI}+)$ mode, at 10,000 resolution power, using a BPX-DXN $(60 \mathrm{~m} \times 0.20 \mathrm{~mm} \times 0.25 \mu \mathrm{m})$ (SGE, Analytical Science, Melbourne, Australia) capillary column. Metals were digested in acid using a Multiwave 3000 (Anton Paar, Graz, Austria) micro wave digestion oven and measured wit atomic absorption spectrometer ( $\mathrm{Tl}, \mathrm{Mn}, \mathrm{Cd}, \mathrm{Pb}, \mathrm{Cr}, \mathrm{Co}, \mathrm{Ni} \mathrm{Cu}, \mathrm{V}$, As and $\mathrm{Sn}$ ) or cold vapour atomic adsorption spectroscopy apparatus $(\mathrm{Hg})$. VOC were sampled using 
headspace solid phase micro extraction (SPME) and determined using gas chromatography/mass spectrometry.

\subsection{Environmental fate modelling}

The model employed for predicting air concentrations of PCBs and PCDD/Fs was SoilPlus (Ghirardello et al., 2010). SoilPlus is a dynamic multimedia model which comprises a multilayered soil and a dual layer atmospheric compartment. The lower air compartment varies hourly in height to reflect planetary boundary layer (PBL) changes. SoilPlus was run simulating in-place pollutants for each PCDD/Fs homologue class and 18 PCB congeners to match those measured (Colombo et al., 2013) in air. (listed in Table SI 3). The selected scenario for the simulation is described in details in S.I. Briefly, single PCB congener and single homologue class simulations were run using physical chemical properties and halflives from (Mackay et al., 1992a, 1992b) with PBL heights from Morselli et al., 2012 and soil properties as in Table SI 1. The model was run hourly for one year for each selected PCB or PCDD/F homologue class, setting as initial concentration the weighted average of the concentrations of the three areas. Air concentrations were then calculated for the corresponding period (usually 8-10 days) of air concentrations measurement. The fingerprints of PCB (obtained calculating 216 values), PCDD/F (100 values) concentrations in air calculated by the model were then compared to the measured fingerprints in the PCA analysis.

\subsection{Microbiological analysis: $16 S$ rRNA hypervariable tag analysis}

The soil samples were microbiologically analyzed to describe the diversity of bacterial communities within the studied areas, in order to find a possible relation with the different contaminant fingerprint. Sequencing data were produced by means of 454 pyrotag assays using universal-bacterial primers targeting variable regions of the $16 \mathrm{~S}$ rRNA gene. The high-quality $16 \mathrm{~S}$ rRNA gene sequences were then clustered into operational taxonomic units (OTUs). The full description of the materials and methods used for the 16S rRNA hypervariable tag analysis, including the workflow scripts and commands is available in the Supplementary Information.

\subsection{Statistical analysis}

Principal component analysis was used to compare the fingerprints of PCBs, PCDDs and PCDFs in the same phase (air or soil) in order to identify a possible common origin of the chemicals. PCA was performed using a software developed by one of the authors according to the standard method (Lebart et al., 1982; Saporta, 1990). Cluster analysis was used to group samples according to the different classes of chemicals analyzed (PCBs, PCDDs, PCDFs, Metals, VOCs) in the different areas (A, R, T). Normalized variable values were used. Regarding microbiological analyses, the biotic dataset represented by the OTU table obtained from QIIME was first filtered removing the under-represented OTUs (threshold of $0.01 \%$ ). The resulting table (254 OTUs) was normalized by Z score in order to avoid clustering driven by the raw abundance and the new matrix was subjected to hierarchical clustering analysis (Murtagh, 1985) using the Euclidean distance index using R (cran.r-project. org, last accessed April 8, 2014). The heatmap graphic representation was also generated using $\mathrm{R}$.

\section{Results and discussion}

\subsection{Concentrations of contaminants in soils}

Caffaro factory produced in the past 80 years many industrial chemicals and pesticides; most of them were chlorinated (Ruzzenenti, 2001) or contained arsenic (such as some pesticides). The soils of the SIN were analyzed for 74 PCB congeners (Table SI 4 reports concentrations at congener level). Average total PCBs (sum of homologues for each class of chlorination measured in the samples) were about $1-2 \mathrm{mg} / \mathrm{kg}$ d.w. in the three pooled samples (Table SI 5). PCB 209 represented the most abundant congener (10-27\% of total PCBs), with concentration between 0.14 and $0.43 \mathrm{mg} / \mathrm{kg}$ d.w. It has to be noted that PCB 209 was not measured originally when the agricultural area contamination was found by the regional authorities in 2001, therefore the presence of this congener considerably raises the levels of total PCBs obtained previously. PCB 209 resulted from the production of Fenclor DK (containing prevalently the decachlorinated congener) which characterized and can be considered a marker of the Brescia Caffaro site (De Voogt and Brinkman, 1989).

PCDD/Fs (Tables SI 6 and 7) concentrations were between 19 and $60 \mathrm{pg}$ WHO05-TEQ/g (26-77 pg I-TEQ/g), which is considerably higher than the average for surface soil measured in the same region (Vives et al., 2008) (Pavia province, which can be considered a control area) (3.18 pg I-TEQ/g) and they are comparable to PCDD/F concentrations found in soils affected by industrial accidents (Umlauf et al., 1999) or sewage sludge (Fiedler, 1996). Additionally, the highest contribution to TEQ is mostly due by PCDFs (87-97\%) which are well known impurities in PCB production (UNEP, 2003; IARC, 2015). Dioxin Like-PCBs (DL-PCBs) have lesser importance, being between 2 and $6 \mathrm{pg}$ WHO05-TEQ/g. However, such concentrations are in the range or higher of the PCDD/Fs I-TEQ measured in the same region (Vives et al., 2008).

Among VOCs (Table SI 8), significant amounts of tetrachloromethane (191-1077 $\mu \mathrm{g} / \mathrm{kg})$, chloroform $(15-22 \mu \mathrm{g} / \mathrm{kg})$ as well as traces of di- and tri-chlorobenzenes. were found. Tetrachloromethane in soil may derive from groundwater outgassing, since a tetrachloromethane plume in groundwater, originated from the Caffaro plant was found by the local regional environmental authorities (ARPA, 2015). However, further investigations are needed to confirm such possibility. A similar situation of a groundwater contamination located at a large contaminated site is that of Bitterfeld/Wolfen in Germany, where hexachlorocyclohexanes (HCHs) were found, deriving from local chemical production plant (Wycisk et al., 2013). A qualitative analysis also showed the presence of DDE, PCNs (polychloronaphtalenes), PCTs (polychlorotriphenyls) and lindane.

Trace elements (Table SI 9) were present at relatively high concentrations, especially lead $(200-400 \mathrm{mg} / \mathrm{kg})$, arsenic (27-79 mg/kg), manganese (around $800 \mathrm{mg} / \mathrm{kg}$ ), mercury (total $\mathrm{Hg}$, up to $4 \mathrm{mg} / \mathrm{kg}$ ). Their presence can be related to the production of pesticides by the Caffaro plant and the chloro-alkaly technology $(\mathrm{Hg})$. Although the presence of so many contaminants may deserve attention, further considerations will be mostly centered on $\mathrm{PCB}$ and PCDD/F.

\subsection{Comparison between $P C B$ fingerprints of measured samples and predicted data}

Since air concentrations and some emission fingerprints (from incinerators and industrial sources mainly) were available in previously published papers (Colombo et al., 2013; Fattore et al., 1997, 2003), we decided to evaluate the hypothesis that PCB concentration in air was related to soil secondary emission (possibly 
including the plant site). PCBs are ubiquitous pollutants and their presence in air could be explained by emission from other sources, such as incineration of waste, cement plants, or other sources (UNEP, 2003). Recently, a number of PCB congeners and PCDD/F classes were measured (Colombo et al., 2013) in air in Brescia at 5 points at different distances (A to E, up to $2 \mathrm{~km}$ ) from the Caffaro plant. Colombo et al. compared the fingerprints of these air concentrations to different sources as an urban waste incinerator and traffic tunnel air measured in the literature and concluded that PCB and PCDD/Fs had different sources. PCBs seemed to be related to the Caffaro plant while PCDD/Fs were closer to steel plant emissions. Additionally, the air concentrations measured in Brescia were substantially higher than background concentrations for PCBs (hundreds to thousands $\mathrm{pg} / \mathrm{m}^{3}$ for total $\mathrm{PCBs}$ ) and average for PCDD/Fs (0.04-0.05 pg WHO05-TEQ/m³ (Colombo et al., 2013). In order to verify whether air concentrations measured could be due to the emission from the contaminated area, we ran congener specific simulations (for PCBs) using selected physical chemical properties (Mackay et al., 1992a, 1992b), and scenario properties as in Table SI 2. The model used was a multimedia air/soil fugacity model (SoilPlus), developed by our group (Ghirardello et al., 2010), which simulates a multilayered soil (layer thickness of $0.5 \mathrm{~cm}$ ) and a dynamic double layer air compartment derived from the AirFug model (Morselli et al., 2011). In such a dynamic air compartment, the lower part fluctuates hourly in response to the variations of the planetary boundary layer. The incorporation of such fluctuations in the model allows us to calculate more accurate air concentrations (with an hourly resolution) than a model with fixed air compartment height. The PBL height depends on insolation and wind speed and so varies, with a diel pattern and also seasonally. For example, Morselli et al. (2011) were able to accurately predict the pattern of air concentration variation of PCBs in air measured in the city of Zurich (Switzerland) (Gasic et al., 2009). Therefore, the use of such dynamic models allows us to predict the air concentration variations resulting from the volatilization of PCBs and PCDD/Fs in soil, accounting for the change of physical chemical properties (vapor pressure and solubility) with temperature, simulating the prevalent PBL conditions during sampling times. We then predicted air concentrations for the same sampling periods of those measured with a high-volume sampler (Colombo et al., 2013). The predicted and measured concentrations were then compared (as supplementary samples, also in the other PCAs) using principal component analysis, together with fingerprints from typical PCB sources. The two principal components explain $43.4 \%$ and $19.2 \%$ of the total variance. The PCA score plot of the PCB air concentrations (Fig. 1) shows three main clusters: air samples from incinerators and tunnels form the first two clusters while the third one is the cluster of predicted/ measured (point A to E of the Colombo et al. paper) concentrations. This last cluster, characterized by comparable fingerprints, may show a common origin, different from those of incinerators and tunnel related samples. Additionally, a gradient is apparent from the PCA score plot: both measured and predicted air concentrations group together in the top section of the cluster for the warm sampling/prediction months (July-August) while they group in the bottom part of the cluster for the colder sampling/prediction months. This behavior reveals that a temperature dependence of air concentrations is apparent, which indicates that the probable source is volatilization from soil and from the contaminated site itself (Wania et al., 1998). This is valid for all the adjacent sampling points ( $A$ to $D$, where the point $D$ approximately corresponds to the agricultural soil areas measured in this work). Point B, roughly corresponding to the Caffaro factory site has indeed shown the highest concentrations in air (Colombo et al., 2013). Fingerprints for Point $\mathrm{E}$ (at about $2 \mathrm{~km}$ west of the soils and the industrial plant) are more scattered, possibly showing a dilution effect of the source strength with distance (with this we mean that PCB occurring in air from distant sources can alter the fingerprints and "dilute" the ratios). These results confirm that the contaminated area is still a current and important secondary source of PCBs to the surrounding regions. A comparison between measured and predicted concentration in air was not possible for the most abundant congener in soil (PCB 209) because it was not present in the measured concentrations dataset (Colombo et al., 2013). However, PCB 209 was found (Tremolada et al., 2015) in soil samples of the Andossi Plateau, a mountain location about $150 \mathrm{~km}$ away from the Brescia site. Given the lack of PCB 209 in Fenclor and Aroclor mixtures (apart from Fenclor DK) this can be a confirmation of the possibility that the Brescia site could be the origin of PCB 209 found. However, PCB 209 may also derive from other sources such as phtalocyanine pigments and tetrachlorophthalic acids and related pigment and other products which have decachlorobiphenyl as marker congener (Anezaki and Nakano, 2014). Additionally, residues from chlorinated solvent production may contain high levels of decachlorobiphenyl in the residues (Zhang et al., 2015). The plot of the variables used to build the PCA reveals (Fig. SI-2) that the main congeners responsible for the measured and predicted concentrations are some of the indicator PCBs, from PCB 28 to PCB 52 and PCB 101.

\subsection{Comparison between PCDD/F fingerprints of measured samples and predicted data}

Similar to what was shown above, predicted PCDDs/Fs air concentrations (using the soil concentrations measured for each chlorination class as input) were compared to the measured air concentrations (as well as for fingerprints of selected sources) reported from Colombo et al. (2013). In this case, total amounts of PCDDs/Fs for each class of chlorination (from tetra-to octa-chlorinated) were used. Given the rather different concentrations in soils of PCDDs and PCDFs, we decided to analyze them in separate PCAs. Fig. 2(a) shows the resulting score plot for the fingerprint of PCDDs. The two principal components explain $48.1 \%$ and $24.9 \%$ of the total variance. The predicted air concentrations values, in this case, cluster in a single group while the measured values are more spread. No apparent temperature dependence is therefore shown by the predicted air concentrations (compared to the measured ones), possibly identifying a different emission source other than secondary soil emissions. This is also confirmed by the fact the measured concentrations do not cluster according to sampling points, indicating again a random fluctuation of congener class influence. The predicted (as well as the measured) air values show a fingerprint much closer to that related to the steel plant fingerprint, although some of the measured points do variate according to some incinerator and tunnel fingerprints. This can be explained by the presence in the area surrounding Brescia of several active steelworks, given the still substantial industrial nature of this area. When looking at the variables (Fig. SI 3), they show a trend on the second axis, which discriminates according the variation of number of chlorine (from the penta-tetra all the way to the octa-chlorinated class, from negative to positive values).

For the PCDFs analysis, the two principal components explain $38.9 \%$ and $24.4 \%$ of the total variance. When comparing PCDF fingerprints (Fig. 2 b), the predicted air concentrations here cluster again (although with a little more spread) while the measured air concentrations are more scattered. The fingerprint of the measured air concentrations is between the predicted, the tunnel and the incinerator ones. Points A to E are randomly distributed in the group of measured concentrations and no precise trend is visible. Looking at the factors responsible for this distribution on the axes (Fig. SI 4) it appears that tetra and penta chlorinated furans are the 


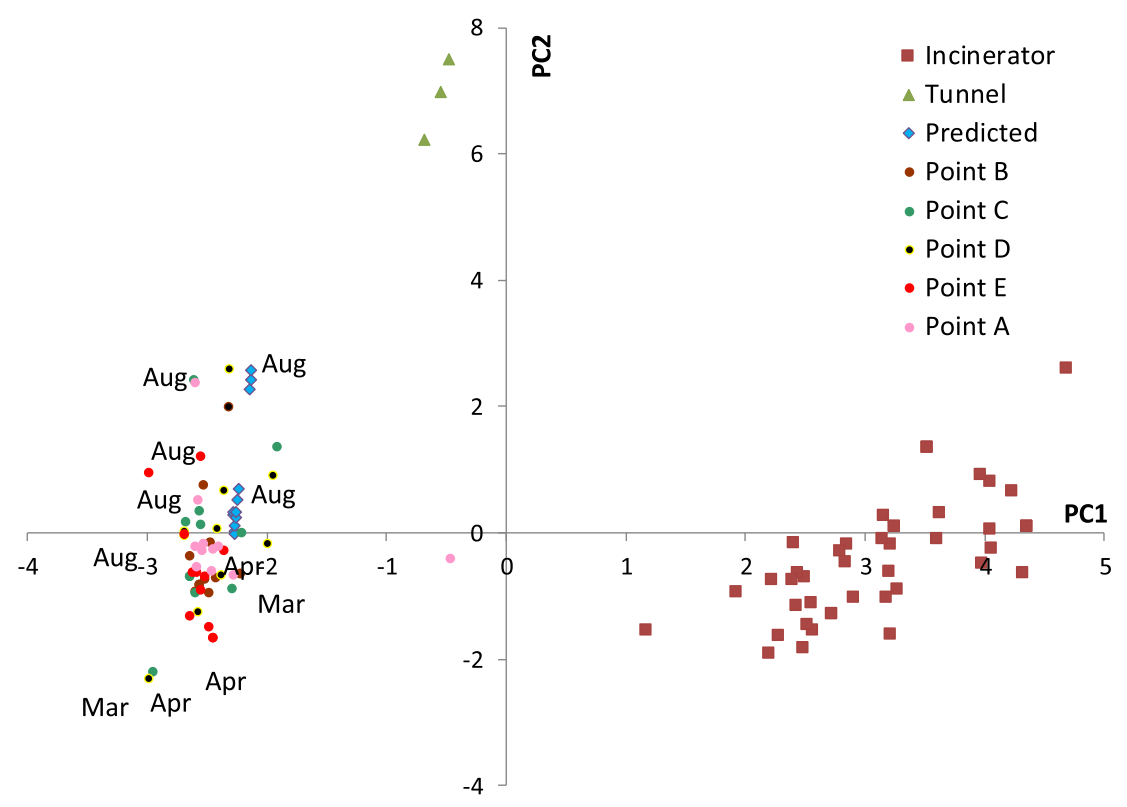

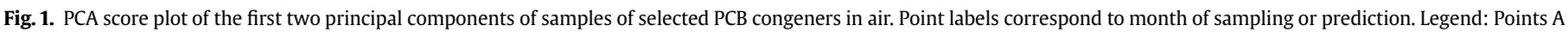
to E, Tunnel, and incinerator fingerprints (Colombo et al., 2013). Predicted values are from this work.

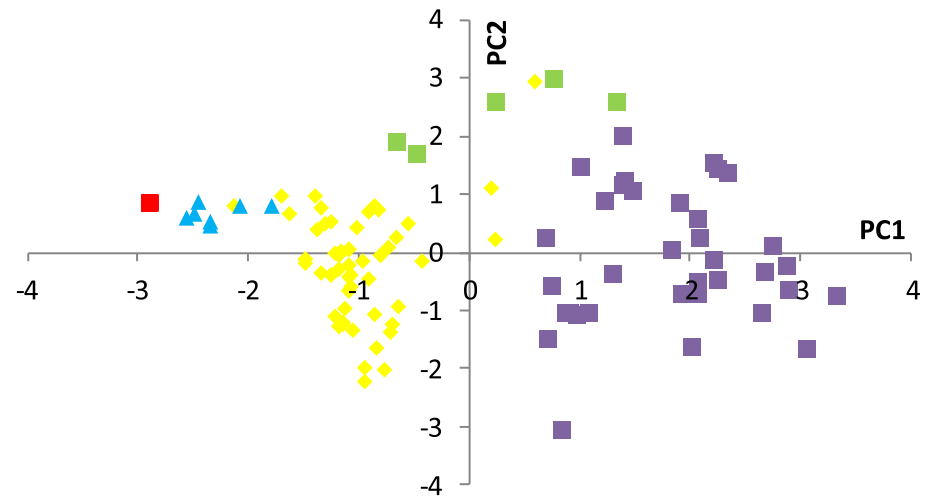

(a)

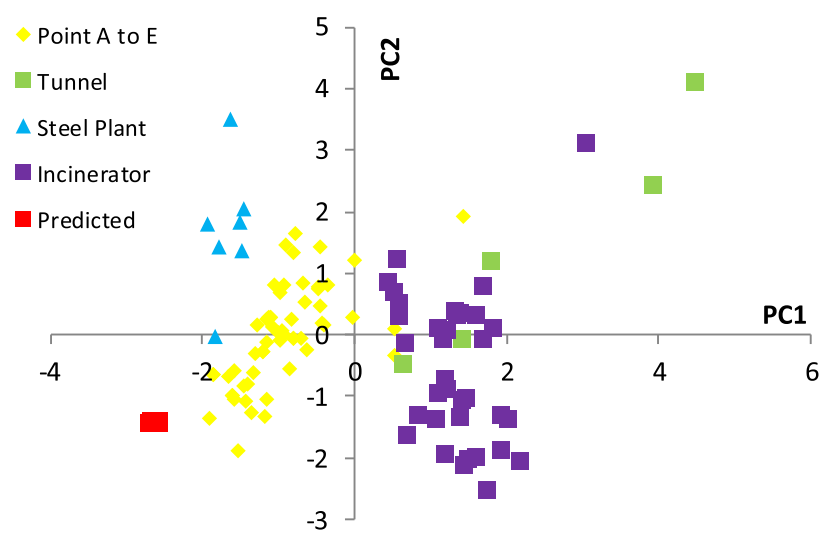

(b)

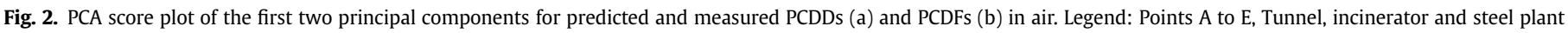
fingerprints (Colombo et al., 2013). Predicted values are from this work.

main drivers of the measured and predicted fingerprints, while more chlorinated classes are more characteristic of the tunnel and incinerator points. This is consistent with PCDFs being derived by impurities in PCB production, where tetra, penta and to a lesser extent hexa-chlorinated furans are the main impurities (IARC, 2015). Additionally, 1,2,3,4,7,8-hexachlorodibenzofuran in soil is higher than the 1,2,3,6,7,8- hexachlorodibenzofuran in all samples and this is a further marker of PCDFs as derived from PCB impurities, as shown by Wakimoto et al. (1988), who measured PCDFs in commercial PCB mixtures. The closeness of the measured concentrations to the predicted ones in the PCA score plot indicates a higher influence of the volatilization of furans from soil (compared to dioxins) in driving air concentrations. This is consistent with the much higher PCDF concentrations than PCDDs in soils and the origin of PCDFs as PCB impurities, travelling and redistributing to the agricultural soils with irrigation.

The comparison between the fingerprints in air of predicted and measured concentrations showed that the contaminated area does not significantly affect air concentrations for PCDDs, while this seems more evident for PCDFs, especially for less chlorinated (and more volatile) congeners, although some current sources are apparently more influent for more chlorinated congeners. These results show the importance of the fingerprinting analysis which can be considered as a guidance tool to discriminate potential sources and direct further studies.

\subsection{Comparison between PCB fingerprints of soil samples and technical mixtures}

In order to evaluate the fingerprint of PCBs in soil, a PCA analysis was carried out comparing the congener composition of the soil samples to aroclor fingerprints (Frame et al., 1996a, 1996b). The objective was to focus the current fingerprint of PCBs in soil after more than 50 years of indirect loading via irrigation water, and the more recent deposition/degassing and weathering related phenomena occurred in soil. Aroclor were commercial mixtures of 
PCBs produced by Monsanto and their composition can be used to evaluate the current composition of PCBs in soil. This was done since Fenclor and Apirolio composition was not available although De Voogt and Brinkman (1989) report that some comparison can be made considering the approximate chlorine percentage in weight. Data for several mixtures were available for each group of $12 x x$ aroclors (from 1216 to 1262) in the increasing degree of chlorination. Aroclor congener data were selected among those measured for the soil samples in order to properly compare the results. PCB 209 was excluded from the comparison since it was not present in the available aroclor composition. The resulting PCA plot is available in Fig. SI 5. The first component explains 51.4\% of the total variance while the second component $29.5 \%$. The composition of PCB in the average soil samples is characterized by a relatively high degree of chlorination and is situated in between the fingerprints of Aroclor 1254 to 1260-1262. This shows that the mixture in the soil samples is composed by generally high molecular weight compounds, as found previously (Turrio-Baldassarri et al., 2009). It must also be remembered that PCBs in Brescia soil have undergone a process of weathering due to the long production time (about 50 years), use, dispersal and time elapsed since the production stopped (in mid '80s). However, given the type of samples collected, the fingerprint presented here can be considered an average of PCBs which did not substantially move (top soil) and those which may have migrated downwards (lower depth sampled).

\subsection{Comparison between $P C D D / F$ fingerprints of soil samples and known sources}

Soil fingerprints for dioxins and furans in Brescia SIN samples were compared to the corresponding data of source related fingerprints from literature. Since the city of Brescia is characterized by numerous types of sources (a large volume urban waste incinerator, steel plants, contaminated soils, traffic, etc.), it may be useful to compare the current situation (historic soil contamination) to the deposition of dioxins/furans from selected type of sources. The objective again is to apportion the sources, at least in qualitative (fingerprint) terms. Sources were selected basing on the availability of representative fingerprints for dioxin and furan classes (sum of all the homologues in each chlorination family) measured in surface soils and available in the scientific literature They included soils measured at increasing distances $(100-3000 \mathrm{~m})$ from a municipal waste incinerator in Spain (Schuhmacher et al., 1997), soils in the vicinity $(2400 \mathrm{~m})$ of a hospital waste incinerator in China (Li et al., 2012), soils up to a few km away of an electronic waste recycling site in China (Hu et al., 2013), soils within a few hundred meters from some industrial sources (steel plants, cement plants, glass production, fossil fuel power stations) and soil around (50 m) open waste combustion sources in Campania Region in Italy, where some elevated soil concentrations were recently measured (Raspa and Di Guardo, 2012). Background surface soils from UK and Norway (Hassanin et al., 2005) were also included for comparison. Fig. 3a shows the PCA plot of the different sources for PCDD. The first component explains $58.2 \%$ of the total variance while the second component $25.5 \%$. In this figure it can be seen that the municipal incinerator fingerprint changes according to the increasing distance from the source: the top ones in the graph are the soils closest to the emission source while the bottom ones are those located at farther distances. This behaviour seems to be related to the gradient of HeCDD (close to the source) to TCDD (away from the source) on the PC2 axis (Fig. SI 6), while OCDD can be considered as characterizing other sources (industrial combustion, waste open fires and hospital waste incinerators). When looking at Brescia soil fingerprints for PCDDs, they form a different cluster in a region characterized by a mixture of tetra and penta dioxins (Fig. SI 6). This seem to exclude a large contribution of a specific source for PCDDs in Brescia soil but rather a mixture of those.

PCA for was performed for PCDFs in soils (Fig. 3 b): in this case the first component explains $51.3 \%$ of the total variance, while the second component $31.4 \%$. Brescia soils have a fingerprint somehow overlapping some of industrial combustion and municipal waste incinerator ones, in a region characterized by the gradient TCDF to OCDF bottom to top (Fig. SI 7). Their fingerprint is more spread in the PCA space, possibly denoting unique characteristics of the Brescia site, as the ratio PCDF/PCDD has already shown. Such diversity may be explained by the PCDF impurities in the PCB production plant, (Wakimoto et al., 1988) and the contribution of tetra, penta and hexa-chlorinated furans, as mentioned before. What it can be concluded evaluating the fingerprints is that PCDDs in soil do not resemble current emission sources, apart from relatively distant incinerator, while PCDFs are compatible to PCB impurities as well as industrial and municipal waste incineration. It should be remembered that soil concentrations are also derived by historical contamination of the same sources (and possibly also the Caffaro plant) which may have changed fingerprint over time also due to the changing emission control regulations. Additionally, weathering and natural attenuation of contaminants may have played a role in changing fingerprints. In order to further evaluate such unique composition of organic compounds (as well as of trace elements) and their interaction with bacteria present in soil, additional analyses of $s$ were performed and are illustrated in the following section.

\subsection{Cluster analysis of Brescia SIN soil according to microbiological and chemical data profiling}

In all the areas investigated the 16S rRNA pyrotag libraries reached saturation (data not shown), revealing a high coverage of bacterial diversity (Tables SI-10). The similar number of $\mathrm{OTU}_{97}$ identified $(243 \pm 4)$ indicated that the three areas did not significantly differ in the overall bacterial species richness (Table SI 10). However, a cluster analysis which considered both the presence and the abundance of polymorphic 16S rRNA sequences at species level $\left(\mathrm{OTU}_{97}\right)$ showed that the bacterial communities inhabiting the $\mathrm{R}$ and $\mathrm{T}$ soils were more similar compared to those inhabiting area $\mathrm{A}$ (Fig. 4). Interestingly, the pattern of diversity reflects that described by the cluster analysis performed on the chemical data, especially concerning the main classes of pollutants measured in this study (see Table SI 5-9), suggesting a link between bacterial community structure and soil pollution profile. According to the cluster analysis performed on chemical composition, Area A clusters separately for PCDDs, VOCs and metals, while areas $\mathrm{R}$ and $\mathrm{T}$ cluster separately respectively for PCBs and TCDFs presence. Therefore, PCDDs, VOCs and metals in the soil collected from area A can putatively constitute the drivers which contribute to select a peculiar bacterial community, diversifying this soil from those collected from areas $\mathrm{R}$ and T. A correlation between microbial and pollutant fingerprints indicate that the presence of the contaminants induced a shift in the residing soil microbial community putatively favoring the degradative populations. Structure and composition of soil bacterial communities have been already exploited for the mapping of polluted sites (Mukherjee et al., 2014). Our results further confirm that the taxonomic composition of bacterial communities can be considered a proxy for soil contamination, suggesting the description of their diversity as a further hint to reveal correlations of the microbiota with pollutant fingerprints in site mapping and during its remediation processes.

To disentangle the catabolic capacities related to biodegradation potential of the bacterial communities detected in the soil by $16 \mathrm{~S}$ 


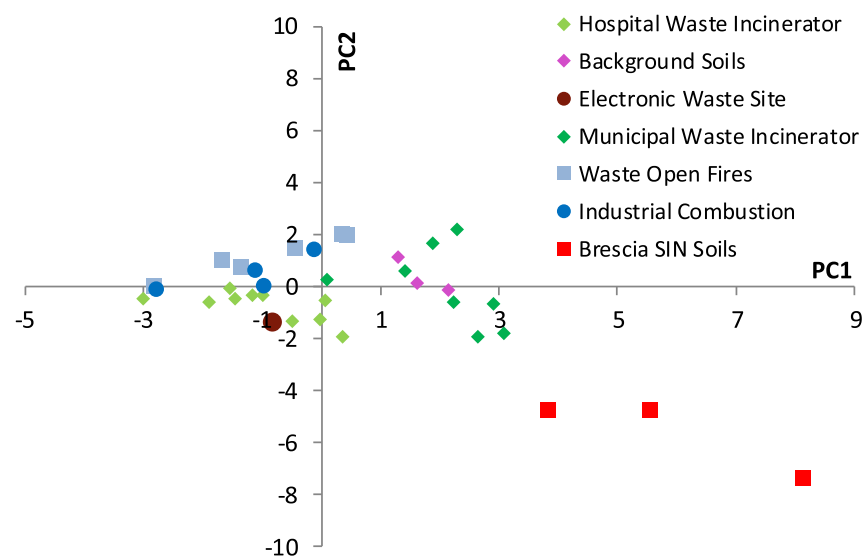

(a)

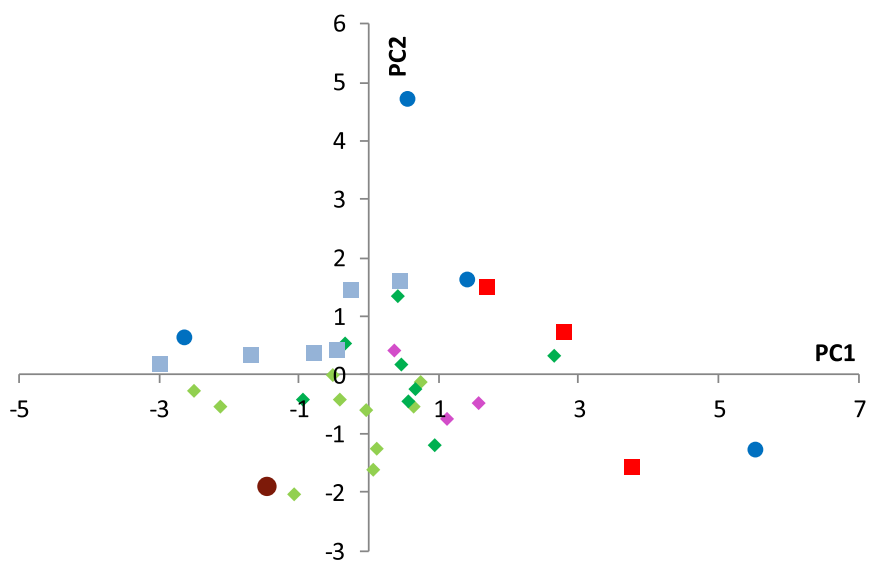

(b)

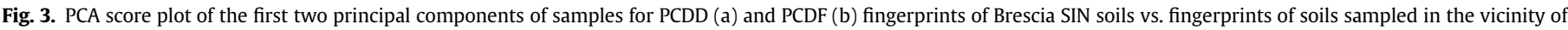

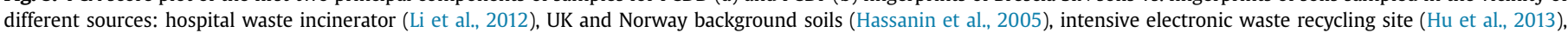
municipal solid waste incinerator at increasing distances (Schuhmacher et al., 1997), waste open fires and industrial combustion sources (Raspa and Di Guardo, 2012).

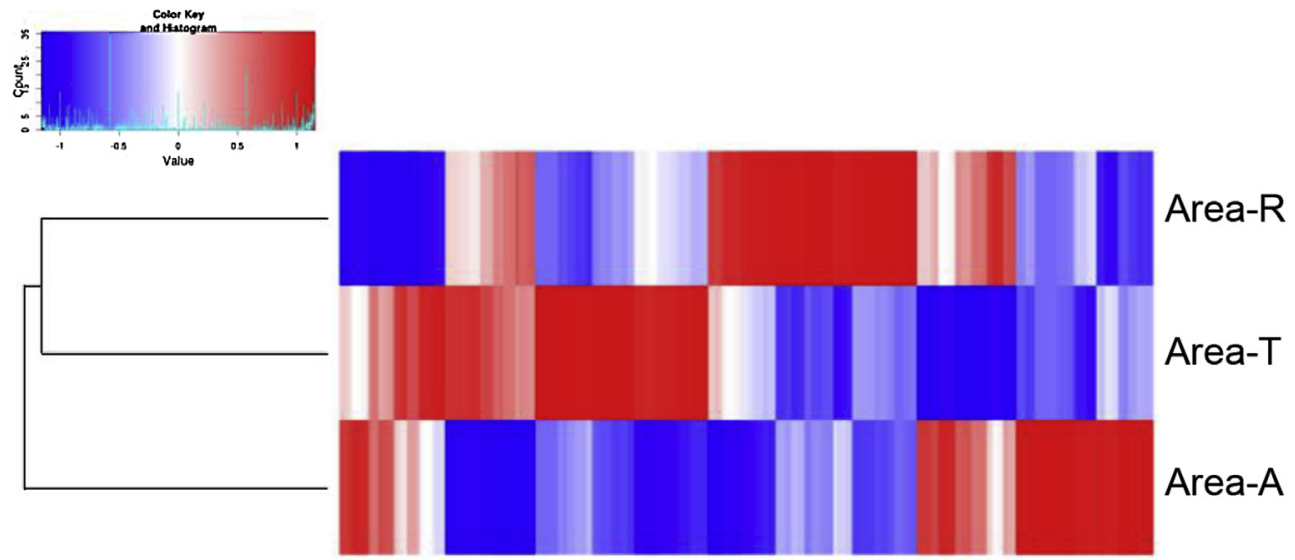

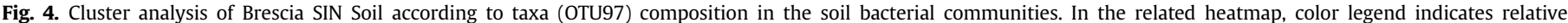
abundances of the taxa. (For interpretation of the reference to colour in this figure legend, the reader is referred to the web version of this article.)

rRNA sequencing, we applied the recently developed software PiCRUST, which infers functional information from the taxonomic data (Langille et al., 2013). This analysis allowed the identification of several metabolisms related to the class "Xenobiotics Biodegradation" within the bacterial communities (Table SI 11). Bacterial taxa potentially harboring these metabolisms were retrieved in all the soils, without significant differences between the three areas. This finding indicates that the selective pressure applied by the high level of contamination potentially lead to the enrichment of a well-adapted bacterial community in all the soils collected from the Brescia SIN, independently from the pollution profile. The presence of metabolic pathways related to xenobiotic modification/degradation harbored by taxonomically distinct bacterial populations in the three areas could be an indication of metabolic redundancy, a trait of relevance in the light of bioremediation which could be potentially supported by a microbiota resilient toward environmental challenges (Kato et al., 2015).

\section{Conclusions}

There is a growing debate on the role of cities and contaminated sites in driving air concentrations of PCBs, PCDD/Fs, in other terms the role of primary vs. secondary sources. The SIN Brescia Caffaro contaminated site and its surrounding areas offer a unique opportunity to evaluate the importance of these sources and reconstruct a possible scenario of contamination which can be used as guidance methodology to evaluate similar situations. There is also a growing interest in coupling measurement and modelling tools to improve the estimate of such emissions. Here we present an innovative comparison of measured and predicted PCBs, PCDD/Fs in air (at single congener/class level) in order to reconstruct the changing fingerprint with time and catch the pattern of chemical volatilizing from soil. This is used to evaluate the current release (and therefore current air contamination) of several sources in a complex situation, where a large contaminated site and a former large PCB factory is present, together with other sources. These results confirm that the contaminated area is still a current and important secondary source of PCBs to the surrounding regions, and to a lesser extent for PCDFs (especially the more volatile), while this is not apparent for PCDDs in air which are mainly affected by other sources. However, the role of the contaminated site at the factory (primary source) is probably still important in driving concentrations in air. When evaluating soils, to assess the extent of historical contamination, we showed that fingerprints for PCBs are related to highly chlorinated mixtures, indicating contamination by these mixtures and/or a long weathering process which has enriched soil 
of less volatile and more recalcitrant congeners. PCB 209 is also recognized as peculiar component in such contamination. When looking at PCDD fingerprints in soil, it can be concluded that they do not resemble those obtained by the contamination produced by current emission sources, apart from relatively distant incinerator sources, while PCDFs are compatible to impurities of PCBs mixtures as well as industrial and municipal waste incineration. However, given the historical contamination, source fingerprint may have changed in time due to different regulations, affecting soil differently in different decades Additionally, weathering and natural attenuation of contaminants may have played a role in modifying such soil fingerprints. Finally, we observed the same soil clustering by applying both chemical and microbiological analyses, the latter aimed at evaluating bacterial phylogenetic and functional diversity, suggesting the use of high throughput sequencing tools as a valuable method to monitor the effect of soil pollutant fingerprints on the soil microbiota, of particular interest during their variation following in situ bioremediation activities.

\section{Acknowledgements}

The project is funded by the Italian Ministry of the Environment and Protection of Land and Sea through Lombardy Region and ERSAF, within the remediation activities of the SIN Brescia Caffaro. FM acknowledges personal support from "Piano di Sostegno della Ricerca 2015-2017: Linea 2 - Dotazione annuale per attività istituzionali" in the project "Microbial Interactions in complex ecosystems (MIRACLE)". Marco Sciaccaluga (ERSAF) is also acknowledged for the help in the soil sampling phase. The authors would also like to thank two anonymous reviewers for their valuable comments and suggestions which improved the quality of the paper.

\section{Appendix A. Supplementary data}

Supplementary data related to this article can be found at http:// dx.doi.org/10.1016/j.envpol.2017.01.033

\section{References}

Anezaki, K., Nakano, T., 2014. Concentration levels and congener profiles of polychlorinated biphenyls, pentachlorobenzene, and hexachlorobenzene in commercial pigments. Environ. Sci. Pollut. Res. 21, 998-1009. http://dx.doi.org/ 10.1007/s11356-013-1977-2.

Apostoli, P., Magoni, M., Bergonzi, R., Carasi, S., Indelicato, A., Scarcella, C., Donato, F., 2005. Assessment of reference values for polychlorinated biphenyl concentration in human blood. Chemosphere 61, 413-421. http://dx.doi.org/10.1016/ j.chemosphere.2005.02.034.

ARPA, 2015. Sito di interesse nazionale "Brescia - Caffaro" monitoraggio acque sotterranee. Risultati delle indagini geochimiche e Piezometriche. Campagna di giugno 2014. Regional Environmental Protection Agency (ARPA) Lombardia Dipartimento di Brescia, Brescia. Downloadable from:http://ita.arpalombardia. it/ita/caffaro/sotterranee.asp.

Bergonzi, R., Specchia, C., Dinolfo, M., Tomasi, C., De Palma, G., Frusca, T., Apostoli, P., 2009. Distribution of persistent organochlorine pollutants in maternal and foetal tissues: data from an Italian polluted urban area. Chemosphere 76 , 747-754. http://dx.doi.org/10.1016/j.chemosphere.2009.05.026.

Bogdal, C., Müller, C.E., Buser, A.M., Wang, Z., Scheringer, M., Gerecke, A.C., Schmid, P., Zennegg, M., MacLeod, M., Hungerbühler, K., 2014. Emissions of polychlorinated biphenyls, polychlorinated dibenzo- $\mathrm{p}$-dioxins, and polychlorinated dibenzofurans during 2010 and 2011 in Zurich, Switzerland. Environ. Sci. Technol. 48, 482-490. http://dx.doi.org/10.1021/es4044352.

Colombo, A., Benfenati, E., Bugatti, S.G., Lodi, M., Mariani, A., Musmeci, L., Rotella, G., Senese, V., Ziemacki, G., Fanelli, R., 2013. PCDD/Fs and PCBs in ambient air in a highly industrialized city in northern Italy. Chemosphere 90, 2352-2357. http://dx.doi.org/10.1016/j.chemosphere.2012.10.025.

Csiszar, S.A., Daggupaty, S.M., Verkoeyen, S., Giang, A., Diamond, M.L., 2013. SOMUM: a coupled atmospheric transport and multimedia model used to predict intraurban-scale PCB and PBDE emissions and fate. Environ. Sci. Technol. 47, 436-445. http://dx.doi.org/10.1021/es3033023.

De Voogt, P., Brinkman, U.A.T., 1989. Production, properties and usage of polychlorinated biphenyls. In: Kimbrough, R.D., Jensen, A.A. (Eds.), Halogenated
Biphenyls, Terphenyls, Naphthalenes, Dibenzodioxins, and Related Products. Elsevier; Elsevier Science Pub. Co., Amsterdam; New York, NY, USA, pp. 1-45.

Diefenbacher, P.S., Gerecke, A.C., Bogdal, C., Hungerbühler, K., 2016. Spatial distribution of atmospheric PCBs in Zurich, Switzerland: do joint sealants still matter? Environ. Sci. Technol. 50, 232-239. http://dx.doi.org/10.1021/ acs.est.5b04626.

Donato, F., Magoni, M., Bergonzi, R., Scarcella, C., Indelicato, A., Carasi, S., Apostoli, P., 2006. Exposure to polychlorinated biphenyls in residents near a chemical factory in Italy: the food chain as main source of contamination. Chemosphere 64, 1562-1572. http://dx.doi.org/10.1016/j.chemosphere.2005.11.057.

Fattore, E., Benfenati, E., Mariani, G., Fanelli, R., Evers, E.H., 1997. Patterns and sources of polychlorinated dibenzo-p-dioxins and dibenzofurans in sediments from the Venice Lagoon, Italy. Environ. Sci. Technol. 31, 1777-1784.

Fattore, E., Di Guardo, A., Mariani, G., Guzzi, A., Benfenati, E., Fanelli, R., 2003. Polychlorinated dibenzo-p-dioxins and dibenzofurans in the air of seveso, Italy 26 years after the explosion. Environ. Sci. Technol. 37, 1503-1508. http:// dx.doi.org/10.1021/es0261224.

Fiedler, H., 1996. Sources of PCDD/PCDF and impact on the environment. Chemosphere 32, 55-64. http://dx.doi.org/10.1016/0045-6535(95)00228-6. Chlorinated Dioxins, PCB and Related Compounds 1994-I.

Frame, G.M., Cochran, J.W., Bøwadt, S.S., 1996a. Complete PCB congener distributions for 17 aroclor mixtures determined by 3 HRGC systems optimized for comprehensive, quantitative, congener-specific analysis. J. High Resolut. Chromatogr. 19, 657-668.

Frame, G.M., Wagner, R.E., Carnahan, J.C., Brown, J.F., May, R.J., Smullen, L.A., Bedard, D.L., 1996b. Comprehensive, quantitative, congener-specific analyses of eight aroclors and complete PCB congener assignments on DB-1 capillary GC columns. Chemosphere 33, 603-623. http://dx.doi.org/10.1016/0045-6535(96) 00214-7.

Gasic, B., Moeckel, C., MacLeod, M., Brunner, J., Scheringer, M., Jones, K.C., Hungerbühler, K., 2009. Measuring and modeling short-term variability of PCBs in air and characterization of urban source strength in Zurich, Switzerland. Environ. Sci. Technol. 43, 769-776.

Ghirardello, D., Morselli, M., Semplice, M., Di Guardo, A., 2010. A dynamic model of the fate of organic chemicals in a multilayered air/soil system: development and illustrative application. Environ. Sci. Technol. 44, 9010-9017.

Glüge, J., Bogdal, C., Scheringer, M., Hungerbühler, K., 2016. What determines РСВ concentrations in soils in rural and urban areas? Insights from a multi-media fate model for Switzerland as a case study. Sci. Total Environ. 550, 1152-1162. http://dx.doi.org/10.1016/j.scitotenv.2016.01.097.

Hassanin, A., Lee, R.G.M., Steinnes, E., Jones, K.C., 2005. PCDD/Fs in Norwegian and U.K. Soils: implications for sources and environmental cycling. Environ. Sci. Technol. 39, 4784-4792. http://dx.doi.org/10.1021/es0505189.

Hu, J., Xiao, X., Peng, P.'an, Huang, W., Chen, D., Cai, Y., 2013. Spatial distribution of polychlorinated dibenzo-p-dioxins and dibenzo-furans (PCDDs/Fs) in dust, soil sediment and health risk assessment from an intensive electronic waste recycling site in Southern China. Environ. Sci. Process. Impacts 15, 1889. http:// dx.doi.org/10.1039/c3em00319a.

IARC, 2015. Polychlorinated and polybrominated biphenyls, vol. 107. IARC Monographs on the Evaluation of Carcinogenic Risks to Humans, Lyon, France (No. 107).

Jamshidi, A., Hunter, S., Hazrati, S., Harrad, S., 2007. Concentrations and chiral signatures of polychlorinated biphenyls in outdoor and indoor air and soil in a major U.K. Conurbation. Environ. Sci. Technol. 41, 2153-2158. http://dx.doi.org/ 10.1021/es062218c.

Johnson, G.W., Quensen III, J.F., Chiarenzelli, J., Hamilton, C., 2006. Chapter 10: Polychlorinated biphenyls. In: Morrison, R., Murphy, B. (Eds.), Environmental Forensics: a Contaminant Specific Guide. Elsevier, Amsterdam, pp. 187-225.

Kato, H., Mori, H., Maruyama, F., Toyoda, A., Oshima, K., Endo, R., Fuchu, G. Miyakoshi, M., Dozono, A., Ohtsubo, Y., Nagata, Y., Hattori, M., Fujiyama, A., Kurokawa, K., Tsuda, M., 2015. Time-series metagenomic analysis reveals robustness of soil microbiome against chemical disturbance. DNA Res. 22, 413-424.

Langille, M.G., Zaneveld, J., Caporaso, J.G., McDonald, D., Knights, D., Reyes, J.A., Clemente, J.C., Burkepile, D.E., Vega Thurber, R.L., Knight, R., Beiko, R.G., Huttenhower, C., 2013. Predictive functional profiling of microbial communities using 16S rRNA marker gene sequences. Nat. Biotechnol. 31, 814-821.

Lebart, L., Morineau, A., Fénelon, J.P., 1982. Traitement des Données Statistiques. Dunod, Paris.

Li, X., Yan, M., Yang, J., Chen, T., Lu, S., Yan, J., 2012. PCDD/Fs in soil around a hospital waste incinerator: comparison after three years of operation. J. Environ. Sci. 24 699-703. http://dx.doi.org/10.1016/S1001-0742(11)60752-3.

Mackay, D., Shiu, W.Y., Ma, K.C., 1992a. Illustrated Handbook of Physical-chemical Properties and Environmental Fate for Organic Chemicals, vol. I. Lewis Publisher, Chelsea, USA.

Mackay, D., Shiu, W.Y., Ma, K.C., 1992b. Illustrated Handbook of Physical-chemical Properties and Environmental Fate for Organic Chemicals, vol. II. Lewis Publisher, Chelsea, USA.

Morselli, M., Ghirardello, D., Semplice, M., Di Guardo, A., 2011. Modeling short-term variability of semivolatile organic chemicals in air at a local scale: an integrated modeling approach. Environ. Pollut. 159, 1406-1412. http://dx.doi.org/10.1016/ j.envpol.2010.12.034.

Morselli, M., Ghirardello, D., Semplice, M., Raspa, G., Di Guardo, A., 2012. Integration of an atmospheric dispersion model with a dynamic multimedia fate model: development and illustration. Environ. Pollut. 164, 182-187. http://dx.doi.org/ 
10.1016/j.envpol.2012.01.039.

Mukherjee, S., Juottonen, H., Siivonen, P., Quesada, C.L., Tuomi, P., Pulkkinen, P., Yrjala, K., 2014. Spatial patterns of microbial diversity and activity in an aged creosote-contaminated site. ISME J. 8, 2131-2142.

Murtagh, F., 1985. COMPSTAT Lectures 4. Multidimensional Clustering Algorithms. Physica-Verlag, Wuerzburg.

Raspa, G., Di Guardo, A., 2012. Analisi spaziale e modellistica dei dati di suolo e sedimenti. In Diossine, Furani e Policlorobifenili Indagine ambientale nella Regione Campania. Quaderni- Laboratorio; ISPRA, Rome, p. 498. Downloadable from:http://www.isprambiente.gov.it/files/pubblicazioni/quaderni/laboratorio/ Quad_Lab_1_2012.pdf.

Ruzzenenti, M., 2001. Un secolo di cloro e ...PCB. Storia delle industrie Caffaro di Brescia. Jaca Book, Milan.

Saporta, G., 1990. Probabilités, analyse des données et statistique. Éditions Technip, Paris.

Schuhmacher, M., Xifró, A., Llobet, J.M., De Kok, H.A.M., Domingo, J.L., 1997. PCDD/Fs in soil samples collected in the vicinity of a municipal solid waste incinerator: human health risks. Archives Environ. Contam. Toxicol. 33, 239-246.

Tremolada, P., Guazzoni, N., Comolli, R., Parolini, M., Lazzaro, S., Binelli, A., 2015 Polychlorinated biphenyls (PCBs) in air and soil from a high-altitude pasture in the Italian Alps: evidence of CB-209 contamination. Environ. Sci. Pollut. Res. 22 19571-19583. http://dx.doi.org/10.1007/s11356-015-5115-1.

Turrio-Baldassarri, L., Abate, V., Alivernini, S., Battistelli, C.L., Carasi, S., Casella, M. Iacovella, N., Iamiceli, A.L., Indelicato, A., Scarcella, C., La Rocca, C., 2007. A study on $\mathrm{PCB}, \mathrm{PCDD} / \mathrm{PCDF}$ industrial contamination in a mixed urban-agricultura area significantly affecting the food chain and the human exposure. Part I: soil and feed. Chemosphere 67, 1822-1830. http://dx.doi.org/10.1016 j.chemosphere.2006.05.124.

Turrio-Baldassarri, L., Abate, V., Battistelli, C.L., Carasi, S., Casella, M., Iacovella, N., Indelicato, A., Rocca, C.L., Scarcella, C., Alivernini, S., 2008. PCDD/F and PCB in human serum of differently exposed population groups of an Italian city. $\begin{array}{lll}\text { Chemosphere } \quad 73, & \text { S228-S234. http://dx.doi.org/10.1016 }\end{array}$ j.chemosphere.2008.01.081.

Turrio-Baldassarri, L, Abballe, A Casella, $\mathrm{M}$, di Domenico, A Jacovella, $\mathrm{N}$, Rocca, C., 2005. Analysis of 60 PCB congeners in drinkable water samples at 10-50 pg/L level. Microchem. J. 79, 193-199. http://dx.doi.org/10.1016/ j.microc.2004.08.011.

Turrio-Baldassarri, L., Alivernini, S., Carasi, S., Casella, M., Fuselli, S., Iacovella, N. Iamiceli, A.L., La Rocca, C., Scarcella, C., Battistelli, C.L., 2009. PCB, PCDD and PCDF contamination of food of animal origin as the effect of soil pollution and the cause of human exposure in Brescia. Chemosphere 76, 278-285. http:/ dx.doi.org/10.1016/j.chemosphere.2009.03.002.

Umlauf, G., Barbiere, M., Facchetti, S., 1999. Recent levels of PCDD/Fs in the terrestrial ecosystem of Seveso. Organohalogen Compd. 44, 311-314.

UNEP, 2003. Standardized Toolkit for Identification and Quantification of Dioxin and Furan Releases. UNEP Chemicals. United Nations Environment Programme, Geneva, Switzerland.

Wania, F., Haugen, J.-E., Lei, Y.D., Mackay, D., 1998. Temperature dependence of atmospheric concentrations of semivolatile organic compounds. Environ. Sci. Technol. 32, 1013-1021.

Weber, R., Gaus, C., Tysklind, M., Johnston, P., Forter, M., Hollert, H., Heinisch, E., Holoubek, I., Lloyd-Smith, M., Masunaga, S., Moccarelli, P., Santillo, D., Seike, N., Symons, R., Torres, J.P.M., Verta, M., Varbelow, G., Vijgen, J., Watson, A. Costner, P., Woelz, J., Wycisk, P., Zennegg, M., 2008. Dioxin- and POPcontaminated sites-contemporary and future relevance and challenges: overview on background, aims and scope of the series. Environ. Sci. Pollut. Res. 15, 363-393. http://dx.doi.org/10.1007/s11356-008-0024-1.

WHO/IPCS, 1993. Polychlorinated Biphenyls and Terphenyls (No. 140), Environmental Health Criteria. World Health Organization/International Programme on Chemical Safety, Geneva, Switzerland.

Wakimoto, T., Kannan, N., Ono, M., Tatsukawa, R., Masuda, Y., 1988. Isomer-specific determination of polychlorinated dibenzofurans in Japanese and American polychlorinated biphenyls. Chemosphere 17, 743-750. http://dx.doi.org/ 10.1016/0045-6535(88)90254-8.

Vives, I., Müller, A., Umlauf, G., Christoph, E.H., Mariani, G., Skejo, H., Cenci, R.M., Sena, F., Beone, G.M., 2008. Levels of PCDD/Fs and trace elements in superficial soils of Pavia Province (Italy). Environ. Int. 34, 994-1000. http://dx.doi.org/ 10.1016/j.envint.2008.03.003.

Wimmerová, S., Watson, A., Drobná, B., Šovčíková, E., Weber, R., Lancz, K. Patayová, H., Richterová, D., Koštiaková, V., Jurečková, D., Závacký, P., Strémy, M. Jusko, T.A., Palkovičová Murínová, Ľ., Hertz-Picciotto, I., Trnovec, T., 2015. The spatial distribution of human exposure to PCBs around a former production site in Slovakia. Environ. Sci. Pollut. Res. 22, 14405-14415. http://dx.doi.org/ 10.1007/s11356-015-5047-9.

Wycisk, P., Stollberg, R., Neumann, C., Gossel, W., Weiss, H., Weber, R., 2013. Integrated methodology for assessing the $\mathrm{HCH}$ groundwater pollution at the multisource contaminated mega-site Bitterfeld/Wolfen. Environ. Sci. Pollut. Res. 20, 1907-1917. http://dx.doi.org/10.1007/s11356-012-0963-4.

Zhang, Y.-F., Fu, S., Dong, Y., Nie, H.-F., Li, Z., Liu, X.-C., 2014. Distribution of polychlorinated biphenyls in soil around three typical industrial sites in Beijing, China. Bull. Environ. Contam. Toxicol. 92, 466-471. http://dx.doi.org/10.1007/ s00128-014-1226-5.

Zhang, L., Yang, W., Zhang, L., Li, X., 2015. Highly chlorinated unintentionally produced persistent organic pollutants generated during the methanol-based production of chlorinated methanes: a case study in China. Chemosphere 133, 1-5. http://dx.doi.org/10.1016/j.chemosphere.2015.02.044. 